\title{
Peripheral device to quantify grip and pinch capacity of children
}

\author{
Karoline de Paula Bischof ${ }^{1}$, Alessandro Pereira da Silva ${ }^{1}$, Willian Molizane Almeida Motta ${ }^{1}$, \\ André Roberto Fernandes da Silva ${ }^{1}$, Antônio Vinícius Morais ${ }^{1}$, Terigi Augusto Scardovelli ${ }^{1}$, \\ Hélio Martucci Neto ${ }^{1}$, Ana Lúcia Manrique ${ }^{2}$, Silvia Regina Matos da Silva Boschi ${ }^{1 *}$ \\ ${ }^{1}$ Technology Research Center, University of Mogi das Cruzes, Mogi das Cruzes, SP, Brazil. \\ ${ }^{2}$ Mathematics Department, Pontifical Catholic University, São Paulo, SP, Brazil.
}

\begin{abstract}
Introduction: Grip and pinch movements are important to perform daily activities and to manipulate objects. In this paper we describe the development and evaluation of a peripheral device to quantify cylindrical grip, pulp-to-pulp pinch, pulp-to-side pinch strength and range of motion of children. Methods: Three objects were selected: a door handle, a switch, and a key, which were instrumented with force sensing resistors to analyse the strength. Potentiometers were used to verify the range of motion and micro switches to assure the correct position of the fingers during the movement execution. Thirty volunteers $(8.77 \pm 1.28)$, both male and female, were selected to test the peripheral device functionality. Results: The results determined the minimum necessary strength values for the object activation and maximum displacement, in which the values are $2.5 \mathrm{~N}, 40^{\circ} ; 2.7 \mathrm{~N}$, $55^{\circ}$; and $2.8 \mathrm{~N}, 100 \%$, for door handle object, key object, and switch object, respectively. In the functionally tests, volunteers have shown a superior strength for activating each object and $73.33 \%$ of them have completed the range movement in the key object, $86.67 \%$ in the switch object, and $93.33 \%$ in the door handle object. Conclusion: The developed peripheral device enabled the measurement of range and static and dynamic strength of grip and pinch movements of children.
\end{abstract}

Keywords Strength, Range of motion, Grip, Pinch, Device.

\section{Introduction}

The hand is an important component in the human anatomy (Schieber and Santello, 2004), and its main physical importance is defined by the object manipulation with specific movements, such as the grip and pinch movements (Touvet et al., 2014). The grip and pinch movement control are important to perform activities of daily living (ADL) (Nowak et al., 2013); also, their measure provide relevant data and they are also parameters to verify the stability and the functionality of the hands movements (Butterfield et al., 2009; Hilton et al., 2013; Monteiro et al., 2010).

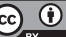

This is an Open Access article distributed under the terms of the Creative Commons Attribution License, which permits unrestricted use, distribution, and reproduction in any medium, provided the original work is properly cited.

How to cite this article: Bischof KP, Silva AP, Motta WMA, Silva ARF, Morais AV, Scardovelli TA, Martucci Neto H, Manrique AL, Boschi SRMS. Peripheral device to quantify grip and pinch capacity of children. Res Biomed Eng. 2018; 34(2):102-109. DOI: $10.1590 / 2446-4740.03017$

*Corresponding author: Technology Research Center, University of Mogi das Cruzes, Av. Dr. Cândido Xavier de Almeida e Souza, 200, CEP 08780-911, Mogi das Cruzes, SP, Brazil. E-mail: boschi@umc.br Received: 12 June 2017 / Accepted: 19 March 2018
To support the rehabilitation process Zhang et al. (2010) have created a glove based on augmented reality by associating it with a virtual piano, with the main goal of rehabilitating the finger movements. Wang et al. (2010) have developed a device for hand rehabilitation combined with augmented reality to reach the hand functionality rehabilitation in an interactive and funny way. Also, Boschi and Frère (2013), have developed a system composed of a virtual environment associated with a peripheral device to evaluate the Range of Motion (ROM) and the grip and pinch strength movement. Other authors have also developed computer games, which were connected to a modified device, so it could offer learning and leisure options for people with severe upper limbs motor limitations (Scardovelli and Frère, 2015). Some studies have also reported the creation of a dynamometer that was easy to manipulate and portable to be used in rehabilitation clinics and hospitals, especially by assisting the clinical evaluation process (Canuto et al., 2016; Lin et al., 2012; Schrama et al., 2014).

These studies are important due to the absence of devices that can provide reliable data to quantify such tasks in clinical evaluations. Therefore, this study describes the development and the test a peripheral device to quantify the static and dynamic strength and 
the ROM of the grip and pinch movement on children by using the objects of ADL.

\section{Methods}

\section{Subjects}

An experimental study was performed with 30 volunteers between 7 and 10 years old $(8.77 \pm 1.28), 60 \%$ male and $40 \%$ female, randomly selected. The number of volunteers was based on the central limit theorem (Kar and Ramalingam, 2013). They were all students at the Sports Department of Guararema, in Sao Paulo, Brazil. The inclusion criteria were based on: minimum age was 7 years old and maximum age was 10 years old, absence of skeletal muscle alterations in upper limbs members, absence of neurological alteration, and preserved cognitive and all volunteers were Taekwondo practitioners, therefore the use of upper limbs was preserved. The study was approved by the Research and Ethics Committee of the University of Mogi das Cruzes (CAAE: 45883715.9.0000.5497), and registered on ClinicalTrials.gov (NCT02965352). All parents or legal guardians of each volunteer consented and signed the authorization form for participation in this study.

\section{Development of the peripheral device}

\section{Selected objects}

Due to the necessity of quantifying the static and dynamic strength of the grip and pinch functional movements, a peripheral device was designed to measure the values of the strength, the performed ROM, and the maintained grip strength during all the arc of movement. The peripheral device was composed by three objects, easy to manipulate. They were associated with ADL objects. The selected objects are widely used in daily life, and they were related to the movements of cylindrical grip (door handle object), pulp-to-pulp pinch (switch object), and pulp-to-side pinch (key object). They were inserted into one board.

\section{Instrumentation and measurement}

To ensure correct positioning of the hand during the grip and pinch movement, micro switches were inserted into each object.

In the door handle object, nine micro switches were used at the side edges. Their arrangement was made to ensure contact of the second phalange of each finger during the movement (except the thumb) (Figure 1a). One side of the door handle were placed 2 pairs of micro

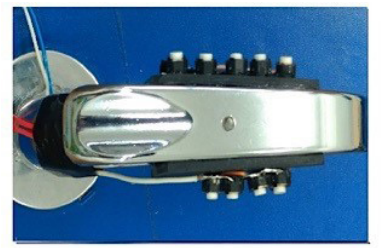

$\mathbf{a}$

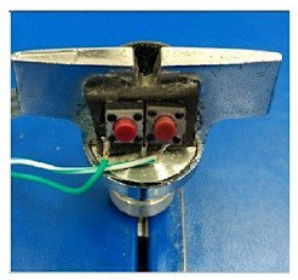

c

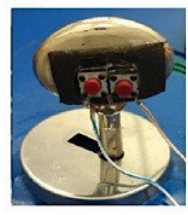

e

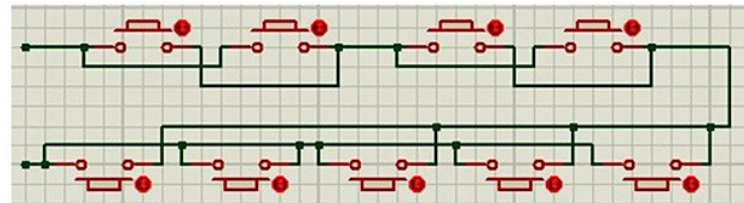

b

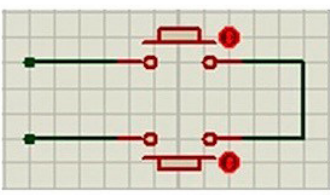

d

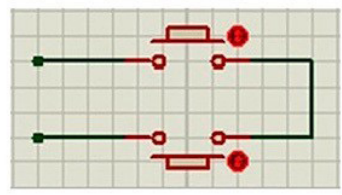

f

Figure 1. Objects used for measurement. (a) Instrumented door handle object; (b) Electrical scheme of the micro switches in parallel and series of the door handle object; (c) Instrumented switch object; (d) Electrical scheme of the micro switches in series of the switch object; (e) Instrumented key object; (f) Electrical scheme of the micro switches in series of the key object. 
switches connected in parallel but with serial connection between them. On the other side were placed five micro switches connected in parallel (Figure 1b).

The linear switch object was instrumented with two micro switches. They were used to ensure the correct positioning of the grip movement of the first phalanx of the volunteer's finger (Figure 1c), connected in series (Figure 1d).

Two micro switches were used on the side of the key object in which the volunteer presses with the side of the index finger (Figure 1e). The micro switches are connected in series between them (Figure 1f).

The sensor FSR, model 402, was used to detect grip and pinch strength (Interlink..., 2017). The FSR 402 used in this study has a detection diameter of $12.7 \mathrm{~mm}$ (Length: $60 \mathrm{~mm}$; Width: $19 \mathrm{~mm}$ ) with a nonlinear characteristic curve, highly repetitive force as low as $2 \%$ and actuation strength as low as 0.1 newton $(\mathrm{N})$ and sensitivity range to $10 \mathrm{~N}$.

For each object, a potentiometer was used to detect a ROM. For the switch object, a linear potentiometer was used and a multi-turn potentiometer was used for the door handle and key objects. The potentiometers used showed an uncertainty in the measurement of 3\% $\pm 0.25 \%$ of the independent linearity. The transfer curve was obtained through the corresponding variation of the potentiometer resistance for each displacement performed.

A linear potentiometer was also used to implement the switch object. This electronic component shows independent linearity of $\pm 0.05 \%$ and a high-resolution level of approximately $0.5 \%$.

The electronic circuit (Figure 2) was divided into: FSR sensor connected to a voltage divider; buffer-based protection implemented with operational amplifier; conditioning with a low-pass 1 st order filter with a cutoff frequency of $1591.5 \mathrm{~Hz}$; and analog control based on an analogue multiplexer (HEF4051B) activated by the micro switches inserted in each object of the peripheral device.

\section{Data acquisition}

Labview ${ }^{\mathrm{TM}}$ software was used to develop the interface and control data acquisition, allowing for storing the strength and ROM values of each executed movement.

\section{Device validation}

The tests were performed with strength sensors and potentiometers (multi-turn and linear). For this, a mathematical model was defined to obtain the values of strength and range of motion, according to the biomechanics of the objects. To perform the test, the

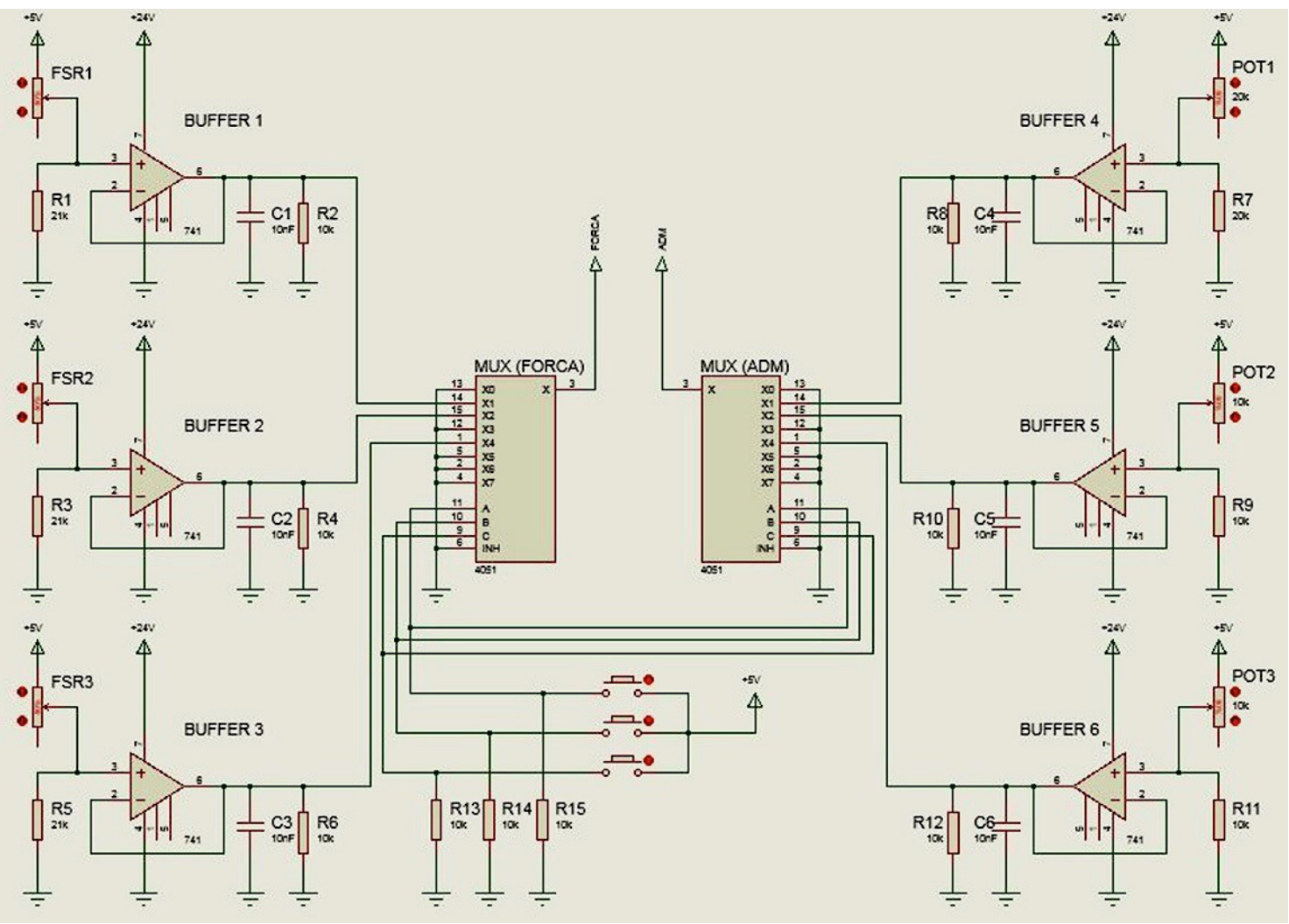

Figure 2. Peripheral device - electronic circuit. 
potentiometers and the strength sensor were inserted into a protoboard. In addition, a test with specific mass $(50 \mathrm{~g})$ was used to establish the characteristic curve of the strength sensor. In this way, the voltage variation was verified in each sensor. The potentiometers were positioned according to the movements with step of $10^{\circ}$. All electrical voltage data were measured with the Agilent digital multimeter, model U1242A, 0.001 voltage resolution. For ROM, the data generated by the door handle object and the key object (Table 1) are indicated in degrees and the switch object in percentage (Table 2). To the strength data obtained were converted from $\mathbf{N}$ to voltage (Table 3 ).

\section{Adjustment procedure for the measuring objects}

To minimize read errors due to residues or interferences, an algorithm has been developed in Labview that uses the zero reference for measurements. In this way, Labview ${ }^{\mathrm{TM}}$ shows the data when sensors and potentiometers are triggered, with no residual values.

\section{Functionality tests with the volunteers}

The tests with the volunteers were made in the Sports Department of Guararema, with a properly authorized schedule, in a classroom, and in the presence of the supervisor.

Table 1. Data conversion: angle $\left({ }^{\circ}\right)$ to voltage $(\mathrm{V})$ for door handle and key objects.

\begin{tabular}{ccl}
\hline Objects & Angle ( $)$ & Voltage $(\mathbf{V})$ \\
\hline Door handle & $0^{\circ}$ & $4.62 \pm 0.009$ \\
& $40^{\circ}$ & $4.58 \pm 0.01$ \\
Key & $0^{\circ}$ & $3.33 \pm 0.01$ \\
& $55^{\circ}$ & $3.31 \pm 0.01$ \\
\hline
\end{tabular}

Table 2. Data conversion: percentage (\%) to voltage (V) for the switch object.

\begin{tabular}{ccc}
\hline Object & Percentage (\%) & Voltage (V) \\
\hline \multirow{4}{*}{ Switch } & 0 & $2.04 \pm 0.02$ \\
& 25 & $2.09 \pm 0.02$ \\
& 50 & $2.35 \pm 0.02$ \\
& 75 & $3.36 \pm 0.02$ \\
& 100 & $4.33 \pm 0.01$ \\
\hline
\end{tabular}

Table 3. Data conversion: strength (N) to voltage (V) for the FSR 402.

\begin{tabular}{cc}
\hline Strength $(\mathbf{N})$ & Voltage $(\mathbf{V})$ \\
\hline 1.0 & $2.05 \pm 0.00$ \\
1.5 & $2.30 \pm 0.17$ \\
2.0 & $2.81 \pm 0.14$ \\
2.5 & $3.03 \pm 0.15$ \\
3.0 & $3.24 \pm 0.15$ \\
3.5 & $3.42 \pm 0.14$ \\
\hline
\end{tabular}

For the performance test, volunteers, one by one, sat in a chair with support for their body. The peripheral device and computer were placed on a table in front of the volunteer. Initially, all necessary explanations about the peripheral device use were performed together with the demonstration of each object and its movements. Volunteers could also manipulate each object before the tests started. The volunteers performed the tests with the right upper limb 3 times, with an interval of 1 minute each. Also, the zero reference of the peripheral device was performed before each test. Data were analysed at the end of all tests.

\section{Data analysis}

For statistical analysis, the absolute frequency, relative frequency, mean and standard deviation were calculated. Thus, for each test the mean of 3 measurements was performed. The D'Agostino statistical test was performed to verify if the sample distribution was parametric or non-parametric. In addition, the correlation between strength and ROM was performed by the Pearson correlation test for the parametric data and by the Sperman correlation test for non-parametric data. For all analysis was considered a significance level of $5 \%$.

\section{Results}

\section{Peripheral device validation}

In the peripheral device developed, each one of the objects was instrumented to capture the strength and the ROM during the execution of the cylindrical grip, pulp-to-pulp pinch, and pulp-to-side pinch movements. The value of the initial and final ROM for the door handle object is from $0^{\circ}$ to $40^{\circ}$, key object is from $0^{\circ}$ to $55^{\circ}$ and the switch object is from 0 to $100 \%$ (values calculated as a percentage).

Table 4 shows the minimum strength $(\mathrm{N})$ values required to actuate each device and the corresponding voltage $(\mathrm{V})$.

\section{Peripheral device functionality tests}

The mean of all strength $(\mathrm{N})$ from the initial contact to the end of the movement was obtained by 3 measurements on three objects. In the analysis of the final mean of the three tests on the key object, the minimum resistance for pulp-to-side pinch was $2.93 \mathrm{~N}$ and the maximum was $3.14 \mathrm{~N}$. On the switch object, the minimum resistance

Table 4. Strength data compared to voltage.

\begin{tabular}{ccc}
\hline Objects & Strength $(\mathbf{N})$ & Voltage $(V)$ \\
\hline Door handle & 2.5 & 3.03 \\
Switch & 2.8 & 3.15 \\
Key & 2.7 & 3.11 \\
\hline
\end{tabular}


for pulp-to-pulp pinch was $2.84 \mathrm{~N}$ and the maximum resistance was $3.10 \mathrm{~N}$. In the door handle object, the minimum resistance for cylindrical grip was $2.49 \mathrm{~N}$ and the maximum was $2.95 \mathrm{~N}$.

Figure $3 \mathrm{a}$ shows the mean initial strength during the displacement of the key object to the end of the test, which corresponds to the pulp-to-side pinch movements achieved by the volunteers. All volunteers showed minimum strength of $2.7 \mathrm{~N}$ during the tests. In addition, all volunteers could achieve the minimum strength required to activate the object in the 3 stages of the test. Some volunteers showed higher strength at initial grip, but decreased during the displacement to the end of the test. Other volunteers started the tests with higher values, which decreased during the displacement but increased at the end of the test.

Figure $3 \mathrm{~b}$ shows the initial displacement value, the value during displacement and the value in the final displacement related to the pulp-to-pulp pinch movement of the switch object. Volunteers have performed a strength value higher than $2.8 \mathrm{~N}$ to activate the switch object.

The door handle object values related to the cylindrical grip movement are shown in Figure 3c. All volunteers activated the door handle with strength greater than $2.5 \mathrm{~N}$.

Key object (a)

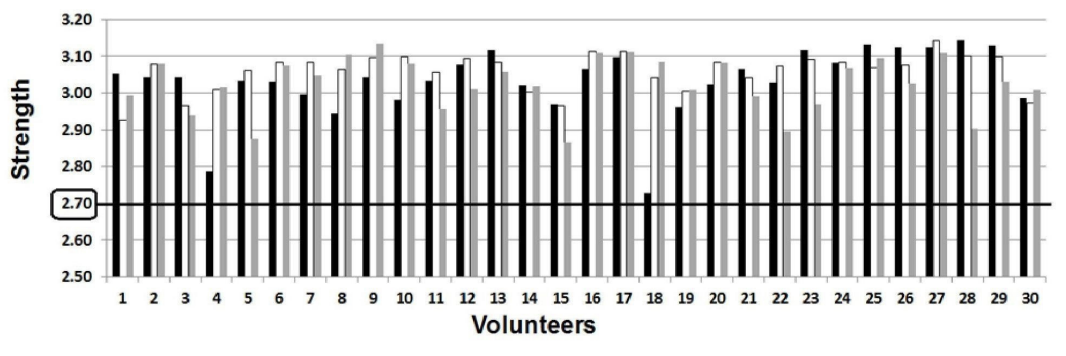

Legend: $\square$ initial $\square$ during the movement $\mathbf{Q}^{-}$finish

Switch object (b)

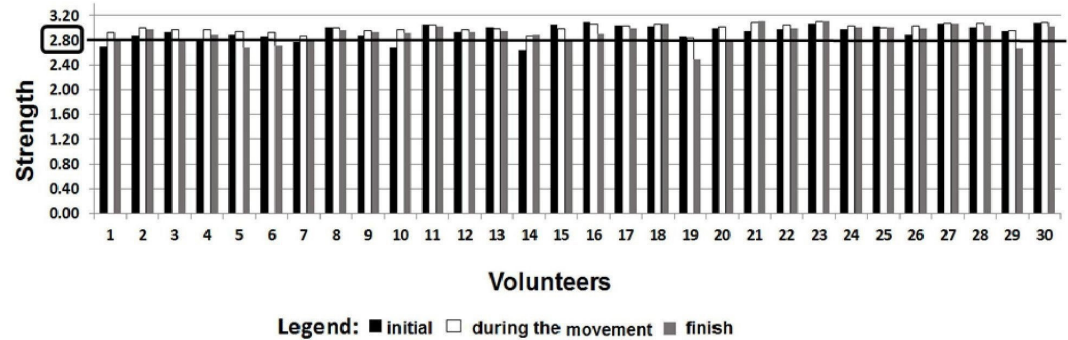

Door Handle object (c)

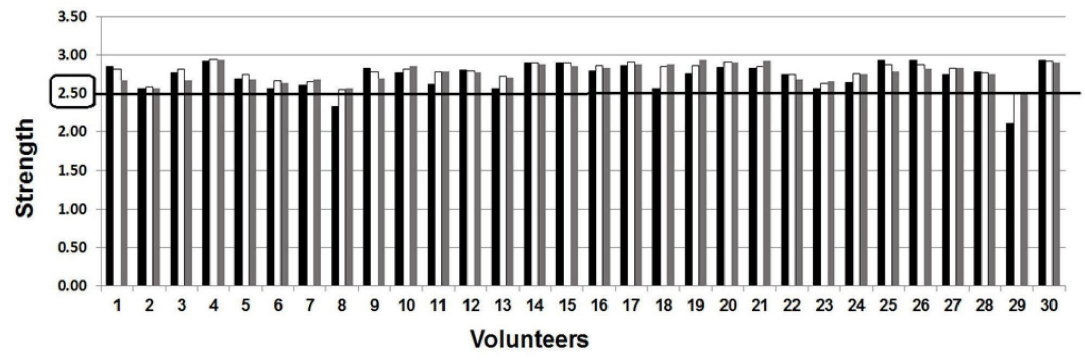

Legend: $\mathbf{m}$ initial $\square$ during the movement $\square$ finish

Figure 3. Values from initial movement to final movement. (a) Measurement of the movement strength on pulp-to-side pinch on the key object; (b) Measurement of the movement strength on pulp-to-pulp pinch on the switch object; (c) Measurement of the movement strength on the cylindrical grip on the door handle object. 

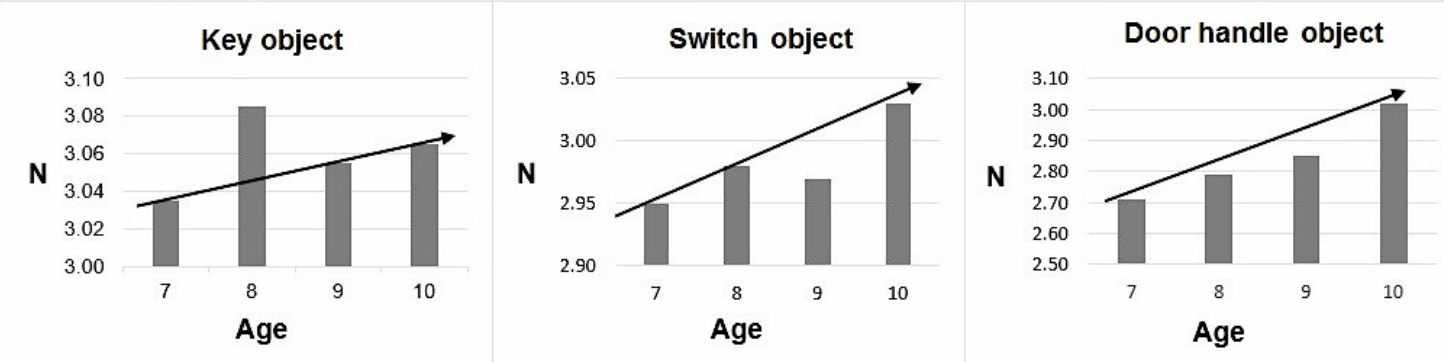

Figure 4. Age versus grip and pinch strength for the different objects tested.

Figure 4 correlates the age of the volunteers with the grip and pinch strength of each object. In the key object, strength tends to increase according to the age, however, all volunteers above 8 years old have shown a higher strength peak. In the door handle object and switch object the strength gradually increased according to a higher age.

When analysing the ROM of each movement, $73.33 \%$ of the volunteers completed the ROM to the end with the key object, when compared with the validation data of the peripheral device $\left(0-55^{\circ}\right)$. With the switch object, $86.67 \%$ completed the movement $(0-100 \%)$. With the door handle object, $93.33 \%$ completed the movement until the final moment $\left(0-40^{\circ}\right)$.

For each object, the correlation between the mean strength for the three grips and ROM was performed. Thus, the Sperman correlation test was used to correlate key object strength and ROM because the sample was not parametric. The results showed a weak correlation between the means with $\mathrm{r}=0.3042$.

For the other analysis, the Pearson correlation test was performed. The switch object showed a very weak correlation between the strength and mean of the ROM, with $\mathrm{r}=0.0324$. The door handle object also showed a weak correlation between the strength and ROM mean with $\mathrm{r}=0.2004$.

\section{Discussion}

The peripheral device allowed to analyze the static and dynamic strength during the whole range of movement, as well as to measure grip strength for the handling of each object. The peripheral devices found in the literature measure strength, an ADL or perform only an analysis of the movements (Duff et al., 2015).

Other authors also developed a peripheral device associated with a game to acquire the data more easily, and they were able to verify the strength limit and ROM (Boschi and Frère, 2013). Strohrmann et al. (2013) measured some ADLs with sensors attached to the body, but they did not quantify these data. Another study associated the use of instrumented gloves to a virtual environment to train movements of daily activity, but also did not quantify these data (Dimbwadyo-Terrer et al., 2016).

Many authors have developed peripheral devices and exoskeletons, but these should be positioned on the upper limb to operate properly (Dovat et al., 2008; Hasegawa et al., 2012; Heo and Kim, 2014). The peripheral device proposed in this paper does not use any sensor positioned for the upper limb of the volunteer, which gave more freedom of movement.

In order to analyze the ROM, all the objects were instrumented with potentiometers, which can allow the measurement of the displacement, indicating if the movement was realized or not. Hasegawa et al. (2012) also used potentiometers in their peripheral device and they could find evidence if the volunteers could complete or not the movement, and also if they could reach the maximum ROM.

Zhang et al. (2010) developed an augmented reality system associated with gloves for the grip and pinch movement, to pick up and manipulate objects. They also provided training with virtual objects, however, the study could not assure the correct location of those movements.

In addition, in this study, Labview ${ }^{\mathrm{TM}}$ was used to record the data and it was possible to record the values of each device from all volunteers individually, which is similar to the study by Bouwsema et al. (2014) who also used Labview ${ }^{\mathrm{TM}}$ to acquire the data to verify the cylindrical grip strength through a prosthesis to assert software efficiency.

Another important feature of the developed peripheral is that it is robust. The selected objects have been securely protected to provide support at the time of handling. They were inserted in a coloured box, to catch the attention of the volunteers when handling it. The interface created through Labview ${ }^{\mathrm{TM}}$ worked as a playful incentive. These data are in agreement with authors who claim to have good results when using more fun peripheral devices (Friedman et al., 2014).

The use of instruments for the strength and quantification of ROM has been a contribution in the search for 
parameters in both strength and evolution of the ROM gain, according to their functionality (Duff et al., 2015).

A limitation of this study is that the developed peripheral device allowed the activation of the key object and door handle only with the right hand.

This study designed and developed a peripheral device with three devices used in ADL. The peripheral device can quantify the static-dynamic strength of movement and ROM of one type of grip - cylindrical grip - and two types of functional pinches -pulp-to-pulp pinch and pulp-to-side pinch in children.

\section{Acknowledgements}

To FAEP, FAPESP, and CAPES for the financial support.

\section{References}

Boschi SRMS, Frère AF. Grip and pinch capability assessment system for children. Med Eng Phys. 2013; 35(5):626-35. http:// dx.doi.org/10.1016/j.medengphy.2012.07.008. PMid:22951038.

Bouwsema H, Van Der Sluis CK, Bongers RM. Effect of feedback during virtual training of grip force control with a myoelectric prosthesis. PLoS One. 2014; 9(5):1-15. http:// dx.doi.org/10.1371/journal.pone.0098301. PMid:24865570.

Butterfield SA, Lehnhard RA, Loovis EM, Saucier D. Grip strength performances by 5- to 19-year-olds. Percept Mot Skills. 2009; 109(2):362-70. http://dx.doi.org/10.2466/pms.109.2.362370. PMid:20037989.

Canuto G, Scardovelli TA, Boschi SRMS, Lopes-Martins RAB, Silva AP. Dinamômetro eletrônico para medição da força em pacientes com mobilidade reduzida. In: Proceedings of the VII Latin American Congress on Biomedical Engineering (CLAIB); 2016 Oct 26-28; Bucaramanga, Colombia. Colombia: CLAIB; 2016. p. 1-4.

Dimbwadyo-Terrer I, Trincado-Alonso F, Reyes-Guzmán ADL, Aznar MA, Alcubilla C, Pérez-Nombela S, et al. Upper limb rehabilitation after spinal cord injury: a treatment based on a data glove and an immersive virtual reality environment. Disabil Rehabil Assist Technol. 2016; 11(6):1-6. http://dx.doi.org/10. 3109/17483107.2015.1027293. PMid:26181226.

Dovat L, Lambercy O, Gassert R, Maeder T, Milner T, Leong TC, Burdet E. HandCARE: a cable-actuated rehabilitation system to train hand function after stroke. IEEE Trans Neural Syst Rehabil Eng. 2008; 16(6):582-91. http://dx.doi.org/10.1109/ TNSRE.2008.2010347. PMid:19144590.

Duff SV, Aaron DH, Gogola GR, Valero-Cuevas FJ. Innovative evaluation of dexterity in pediatrics. J Hand Ther. 2015; 28(2):144-9. http://dx.doi.org/10.1016/j.jht.2015.01.004. PMid:25835255.

Friedman N, Chan V, Reinkensmeyer AN, Beroukhim A, Zambrano GJ, Bachman M, Reinkensmeyer DJ. Retraining and assessing hand movement after stroke using the MusicGlove: comparison with conventional hand therapy and isometric grip training. J Neuroeng Rehabil. 2014; 11:76. PMid:24885076.

Hasegawa Y, Ariyama T, Kamibayashi K. Pinching force accuracy affected by thumb sensation in human force augmentation. In: Proceedings of the IEEE International Conference on Intelligent Robots and Systems; 2012 Oct 7-12; Vilamoura, Portugal. USA: IEEE Computer Society; 2012. p. 3943-8. http://dx.doi.org/10.1109/IROS.2012.6386081.

Heo P, Kim J. Power-assistive finger exoskeleton with a palmar opening at the fingerpad. IEEE Trans Biomed Eng. 2014; 61(11):2688-97. http://dx.doi.org/10.1109/TBME.2014.2325948. PMid:24860025.

Hilton CL, Goloff SE, Altaras O, Josman N. Review of instrument development and testing studies for children and youth. Am J Occup Ther. 2013; 67(3):e30-54. http://dx.doi. org/10.5014/ajot.2013.007831. PMid:23597698.

Interlink Electronics [internet]. Westlake Village; 2017 [cited 2017 June 8]. Available from: http://interlinkelectronics.com/

Kar SS, Ramalingam A. Is 30 the magic number? Issues in sample size estimation. NJCM. 2013; 4(1):175-9.

Lin DCY, Chang J-H, Shieh S-J, Tsai FHJ, Lee YL. Prediction of hand strength by hand injury severity scoring system in hand injured patients. Disabil Rehabil. 2012; 34(5):423-8. http:// dx.doi.org/10.3109/09638288.2011.607550. PMid:21967094.

Monteiro CBM, Jakabi CM, Palma GCS, Torriani-Pasin C, Meira CM. Motor learning in children with cerebral palsy. Rev Bras Cresc e Desenv Hum. 2010; 20(3):11-23.

Nowak DA, Glasauer S, Hermsdörfer J. Force control in object manipulation: a model for the study of sensorimotor control strategies. Neurosci Biobehav Rev. 2013; 37(8):1578-86. http:// dx.doi.org/10.1016/j.neubiorev.2013.06.003. PMid:23791788.

Scardovelli TA, Frère AF. The design and evaluation of a peripheral device for use with a computer game intended for children with motor disabilities. Comput Methods Programs Biomed. 2015; 118(1):44-58. http://dx.doi.org/10.1016/j. cmpb.2014.10.002. PMid:25459524.

Schieber MH, Santello M. Hand function: peripheral and central constraints on performance. J Appl Physiol. 2004; 96(6):2293300. http://dx.doi.org/10.1152/japplphysiol.01063.2003. PMid:15133016.

Schrama PP, Stenneberg MS, Lucas C, Van Trijffel E. Intraexaminer reliability of hand-held dynamometry in the upper extremity: a systematic review. Arch Phys Med Rehabil. 2014; 95(12):2444-69. http://dx.doi.org/10.1016/j.apmr.2014.05.019. PMid:24909587.

Strohrmann C, Labruyère R, Gerber CN, Van Hedel HJ, Arnrich $\mathrm{B}$, Tröster G. Monitoring motor capacity changes of children during rehabilitation using body worn sensors. J Neuroeng Rehabil. 2013; 10:83. PMid:23899401.

Touvet F, Roby-Brami A, Maier MA, Eskiizmirliler S. Grasp: Combined contribution of object properties and task constraints on hand and finger posture. Exp Brain Res. 2014; 232(10):3055-67. http://dx.doi.org/10.1007/s00221-014-39901. PMid:24888535. 
Wang H, Hsu C, Chiu D, Tsai S. Using augmented reality gaming system to enhance hand rehabilitation. In: Proceedings of the 2nd International Conference on Education Technology and Computer; 2010 June 22-24; Shanghai, China. USA: IEEE Computer Society; 2010. p. 243- 6.
Zhang D, Shen Y, Ong SK, Nee AYC. An affordable augmented reality based rehabilitation system for hand motions. In: Proceedings of the International Conference on Cyberworlds; 2010 Oct 20-22; Washington. USA: IEEE Computer Society; 2010. p. 346-53. http://dx.doi.org/10.1109/CW.2010.31. 